\title{
Assistive Mobility Devices focusing on Smart Walkers: Classification and Review
}

\author{
Maria M. Martins ${ }^{\# 1}$,Cristina P. Santos ${ }^{\# 2}$,Anselmo Frizera-Neto ${ }^{* 3}$, Ramón Ceres ${ }^{\S 4}$ \\ " Industrial Electronics Department, University of Minho, Guimarães, Portugal \\ ${ }^{1}$ mariam@dei.uminho.pt \\ ${ }^{2}$ cristina@dei.uminho.pt \\ *Electrical Engineering Department, Federal University of Espirito Santo (UFES) \\ Av. Fernando Ferrari, 514. Vitoria-ES, Brazil \\ ${ }^{3}$ anselmo@ele.ufes.br \\ ${ }^{\S}$ Bioengineering Group, Spanish National Research Council (CSIC) \\ Crta. Campo Real Km 0.200 - Arganda del Rey. Madrid \\ ${ }^{4}$ ceres@iai.cic.es
}

\begin{abstract}
In an aging society it is extremely important to develop devices, which can support and aid the elderly in their daily life. This demands means and tools that extend independent living and promote improved health.

Thus, the goal of this article is to review the state of the art in the robotic technology for mobility assistive devices for people with mobility disabilities. The important role that robotics can play in mobility assistive devices is presented, as well as the identification and survey of mobility assistive devices subsystems with a particular focus on the walkers technology. The advances in the walkers' field have been enormous and have shown a great potential on helping people with mobility disabilities. Thus it is presented a review of the available literature of walkers and are discussed major advances that have been made and limitations to be overcome.
\end{abstract}

Keywords: Assistive mobility technology, Smart Walkers, Rehabilitation 


\section{Introduction}

During the twentieth century the proportion of elderly people had an important rise, and this trend is expected to continue into the twenty-first century. The proportion of population over 60 years old was $8 \%$ in 1950, 10\% in 2000, and it is estimated to reach $21 \%$ in 2050 [1]. Loosing complete or part of mobility, affects not only the ability to walk but also the ability to perform personal tasks, which is a major determinant in life quality and causes dependence of others in daily life.

In an aging society it is extremely important to develop devices, which can support and assist the elderly in their daily life, since their mobility degrades with age. This situation requires a great medical care, incurs large costs and can be fatal in some cases. Elderly tend to have cognitive impairments and experience more serious falls but there is strong evidence that daily exercise may result on fall prevention and postural stability [2]. So, it becomes more and more relevant to find ways and tools to compensate, to improve or to restore and to enhance this mobility.

For several years, researchers have been addressing the needs of persons with mobility disabilities through alternative or augmentative devices [2]. These solutions are selected based on the degree of disability of the user. For the purposes of this review, it will be presented, on the one hand, the alternative devices, which are used in case of total incapacity of mobility. These devices are usually wheelchairs or solutions based on autonomous especial vehicles [3][4]. On the other hand, the augmentative devices are developed to users with residual mobility capacities. They are used to avoid, whenever possible, the inadequate use of alternative devices, thus improving the physical and cognitive capabilities. These elements can be used as mobility-training devices, self-ported devices, such as prostheses or orthoses, or external, such as crutches, canes and walkers.

Among the external augmentative devices, we will focus our review on the walkers. These devices assume an important role, due to the large number of potential users, considering its simplicity and ambulatory potential. They were designed to improve pathological gait, through a support base for the upper limbs that improves the balance of the individuals and reduces the load on their lower limbs [5]. In addition, use the person's remaining locomotion capability in order to move [5], avoiding the early and deteriorative use of wheelchairs. 
Over the past years, technological advances allowed the incorporation of sensors and actuators in conventional walkers, providing the stability of fourlegged walkers, without affecting the resultant naturalness of the users' gait patterns. Besides, these devices enable to identify the movement intentions of the users and therefore control the mobility assistance accordingly.

We intend to cover all of the major developments in the mobility assistive devices described before, particularly focusing on the walker devices. In this review, it is introduced a brief presentation of the causes and consequences of the gait dysfunctions that lead patients to use mobility assistive devices. Then, it is reviewed the literature regarding the corresponding mobility assistive devices. Finally, we focus on the literature regarding the walker' devices, presenting a more detailed review about the various existing models to date. It is presented a discussion of this information, summarizing the major accomplishments in the field and identifying the limitations and challenges to be overcome in future researches.

\section{Gait Dysfunctions}

The causes that affect the human mobility are rarely associated to only one disease [6].

The elderly are the ones that suffer more of mobility disorders, because the age causes a number of changes to mobility. Speed tends to decrease slightly and this is thought to increase efficiency of body motion since less energy is expended per stride. Less speed also allows better compensation of major muscle groups for any difficulties such as pain or weakness and allows less force to descend on any particular joint. There also tends to be some decrease in stride length. A decrease of speed and length may also play a role in maximizing balance and stability and be a natural way of helping prevent excess fall risk. [6]

The danger of falls in elderly people is due to high susceptibility to injuries caused by prevailing diseases e.g. osteoporosis or reduced protective reflexes. Besides the direct risk of fall-related injuries (e.g. major fractures or head trauma) another important consequence of falls is reduced mobility and loss of selfconfidence, which in turn leads, therefore, to a significant reduction of quality of life. [7] 
Disordered mobility, defined as a gait that is slowed, aesthetically abnormal, or both, is not necessarily an inevitable consequence of aging but rather a reflection of the increased prevalence and severity of age-associated diseases. These underlying diseases, neurologic and non-neurologic, contribute to disordered mobility. Elderly patients usually have more than one condition contributing to their mobility disorder.

When asked about difficulties in walking, patients most often cite pain, stiffness, dizziness, numbness, weakness, and sensations of abnormal movement. Conditions seen in the primary care setting that can contribute to mobility disorders include degenerative joint disease, acquired musculoskeletal deformities, intermittent claudication, impairments following orthopedic surgery and stroke, and postural hypotension. Other conditions that cause mobility dysfunctions are hemiplegia, knee and hip diseases and metabolic disorders [6].

Walking is traditionally seen as an automatic motor task that requires little, if any, higher mental functions. However, in the past decade, new insights have drawn attention to the importance of cognition in daily walking. Normal walking requires strategic planning of the best route, as well as continuous interaction with the environment and with internal factors.

Failing to understand the significance of an obstacle, choosing an inappropriate route, or misinterpreting one's own physical abilities can lead to falls. The safety and efficacy of normal walking rely not only on sensorimotor systems, but also critically depend on the interaction between the executive control dimension (integration and decision of action) with the cognitive dimension (e.g. navigation, visual-spatial perception, or attention) and the affective dimension (mood, cautiousness, and risk-taking). A common situation where such integration is challenged is observed when people must walk while performing one or more secondary tasks. Lundin-Olsson and colleagues [8] were the first to note the significance of a failure to maintain a conversation while walking ("stop walking while talking”) as a marker for future falls. The ability to maintain normal walking while performing a secondary task has become the classic way to assess the interaction between cognition and gait.

In elderly people, this dual task ability deteriorates because the central resources decline, due to subclinical disease processes or medication. This deterioration leads to a mismatch between the limited personal resources of elderly 
people and the complexity of the demand (the combined walking and secondary task). As a consequence, elderly people slow down or have increased stride variability (suggesting reduced automaticity) while performing a secondary task during walking. Gait becomes less secure and the risk of falling increases. In patients with overt disease, such as stroke or Parkinson's disease, gait deteriorates even more during dual tasking [9]. It is noteworthy, that the elderly are not the only age group to suffer from mobility disorders. Any person that has cardiovascular problems, strokes, etc, can be affected with the mentioned consequences.

To reduce the degree of mobility disorder, the patient can be exposed to a medical intervention. This intervention is effective, but usually leaves some residual damage that cannot be reverse. Thus, it is important to consider other types of interventions like the use of mobility assistive devices for rehabilitation or functional compensation of the mobility, so that the patient can recover from his dysfunction without injuries.

\section{Mobility Assistive Devices}

Table 1 presents the different categories of assistive mobility devices and the corresponding purposes.

Because of the many available devices and the importance of selecting the best for each individual patient, a formal evaluation should be carried out by an experienced physical therapist before deciding which device is appropriated for the injury. Once the device is indicated, the therapist can make the appropriate equipment adjustments to meet the specifications of each patient and can provide training in the proper use of the device. Potential problems can be assessed by the physical therapist before the device is used [10].

In case of total incapacity of mobility, considering both bipedestation and locomotion, the alternative devices, represented by the wheelchairs and the special vehicles, are the optimal solution. These have been the targets of intensive research, especially considering Autonomous Robotic Wheelchairs (ARW) [11][12][13]. 


\begin{tabular}{|c|c|c|c|c|}
\hline \multicolumn{2}{|c|}{ Mobility Assistive Devices } & Examples & Purpose & $\begin{array}{l}\text { Degree of } \\
\text { incapacity }\end{array}$ \\
\hline \multirow{2}{*}{ 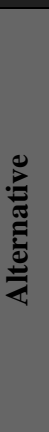 } & Wheelchairs & $\begin{array}{l}\text { - } \text { Manual } \\
\text { - Autonomous with } \\
\text { assistive navigation } \\
\text { and/or bipedestation }\end{array}$ & Transportation & \multirow{2}{*}{$\begin{array}{c}\text { Total } \\
\text { incapacity } \\
\text { of mobility }\end{array}$} \\
\hline & $\begin{array}{c}\text { Autonomous especial } \\
\text { vehicles }\end{array}$ & $\begin{array}{l}\text { - Autonomous vehicles to } \\
\text { improve cognitive } \\
\text { capacities; } \\
\text { - Bipedestation }\end{array}$ & $\begin{array}{l}\text { Transportation. } \\
\text { Improvement of cognitive } \\
\text { capabilities. }\end{array}$ & \\
\hline \multirow{3}{*}{ : } & $\begin{array}{c}\text { Mobility-training } \\
\text { devices }\end{array}$ & $\begin{array}{l}\text { - Parallel Bars } \\
\text { - Treadmill-training } \\
\text { devices } \\
\text { - Ambulatory-training } \\
\text { devices } \\
\text { - Feet-manipulator training } \\
\text { device }\end{array}$ & $\begin{array}{c}\text { Mobility Rehabilitation } \\
\text { Training }\end{array}$ & \multirow{3}{*}{$\begin{array}{l}\text { Residual } \\
\text { mobility } \\
\text { capacities }\end{array}$} \\
\hline & Self-ported devices & - Orthoses & $\begin{array}{l}\text { Functional Compensation } \\
\text { (Supplement the function of the } \\
\text { limbs) }\end{array}$ & \\
\hline & External devices & $\begin{array}{l}\text { - Canes } \\
\text { - Crutches } \\
\text { - Walkers }\end{array}$ & $\begin{array}{l}\text { Functional compensation } \\
\text { (support during walking, to } \\
\text { increase gait stability, and } \\
\text { balance) and rehabilitation } \\
\text { training. }\end{array}$ & \\
\hline
\end{tabular}

Beyond the manual wheelchairs (Figure 1a)) [14], robotic solutions are able to provide for autonomous and assistive navigation to wheelchairs (Smart Wheelchairs) making use of human-machine interfaces, like BCI's (Brain Computer Interfaces) and EMG (electromyography) signals [15][16][17] (Figure 1b). Additionally, some smart wheelchairs also enable a bipedestation position [19] (Figure 1 c)).

Nevertheless, the continuous use of this kind of devices can cause problems of health mainly since the user remains for a long time in a sitting position, these problems include loss of bone mass, osteoporosis, degradation of blood circulation and physiological functions, skin sores, among others. For these reasons considering the remaining locomotion capacities, it is interesting to encourage, whenever possible, the use of augmentative devices [5]. 


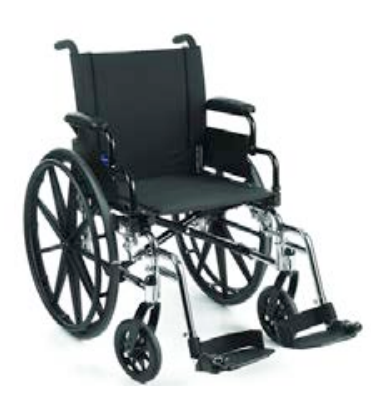

a)

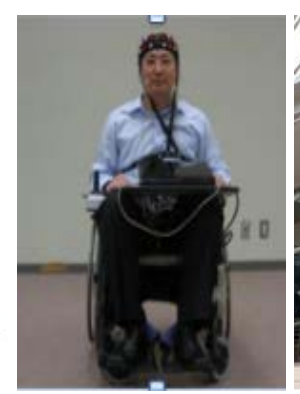

b)

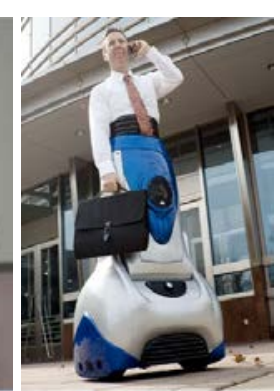

c)

Figure 1 - a) Manual Wheelchairs [14] and Smart Wheelchairs with b) BCI interface [18], and c) bipedestation position [19].

The augmentative devices can help the patient with reduced mobility to avoid the previously presented health problems and allow using the user's patient remaining locomotion capability. In some cases, users can even relearn to walk safely and efficiently, in order to retrieve all the necessary movements for a normal gait. In other cases, these devices actuate like functional compensation elements that assist movements that the patient has lost. This means that the patient can learn new strategies to move, contributing to his independent locomotion on the daily life.

The augmentative devices can be used as 1) mobility-training devices during rehabilitation; 2) self-ported devices such as prostheses and orthoses, or 3) external devices, such as crutches, canes and walkers.

In the following, each of these types of augmentative devices will be described in more detail as well as the motivation for their use and evolution to more robotic systems when appropriate.

\subsection{Mobility-Training Devices}

The mobility-training devices purpose is to help on the rehabilitation of the patient's movements that have gait disabilities.

The most basic mobility-training devices are the parallel bars [20] (Figure 2). Their objective is to help people regain their strength, balance, range of motion, independence and to recover from some injuries, and other debilitating conditions. Patients are required to repeat concise movements that work more than one joint 
and muscle. Parallel bars are also used for ambulatory exercises to improve a patient's ability to walk independently or with assistance. This kind of technique has shown to produce good results in terms of rehabilitation of patients [20].

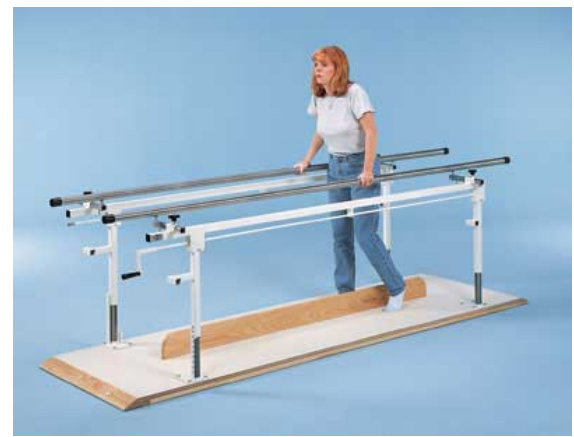

Figure 2 - Parallel Bars [20].

However, this therapy requires the involvement of two or three therapists to assist patients in walking, holding their lower limbs to control movement. Thus, it is required a substantial commitment and effort on the part of therapists [21]

Robotics appears applied to rehabilitation, resorting to the use of robots for mobility training of patients with disabilities.

It is known [22] that a new movement, or a qualitative improvement to an existing movement, can be achieved only through repetitions. Thus, therapy intensively addresses movement repetition in the training. This is the type of tasks that can be attempted by robotic devices. Research on this field led to the existence of robotic mobility training devices capable to expand the work of therapists so that each patient can receive enough therapy to easily attain an optimal recovery.

However, previous studies [23][24][25] have shown that patients have to be intensively engaged on the procedure; otherwise they loose interest with time, resulting in a passive or no participation at all, causing bad results at the rehabilitation level. Their engagement must go beyond the novelty of the first sessions. Robotic mobility training devices are expected to provide to the therapists the necessary assistance to allow the patient to complete a certain task on locomotion; repeat as much as possible cyclic movements while motivating them to actively participate in the training. 
Robotic mobility-training devices can be further divided into three different type of devices, according to the patients' pathologies, as follows: treadmilltraining devices, ambulatory-training devices and feet-manipulator training devices.

The first are the treadmill-training devices, which apply a treadmill while training. Some examples use a partial body-weight support, assisting patients to re-learn walking movements through repetition and task-oriented training. The main aim is to eliminate the need of the patients to deal with balance during the gait, focusing their concentration on the lower limbs movements. Additionally, the body-weight support relieves the patient from his own load. The treadmill-based training devices have been the most common method for mobility training.

The target patients of these devices are neurological target users (stroke, spinal injury, cerebral palsy) [22]. Their training mainly aims at improving the functional movements and sensorial stimulation through repetition. On the literature, there are well known devices like Lokomat [22], Lokohelp [26], LOPES [27] (Figure 3), whose goal is to provide an intensive training on movement repetition.

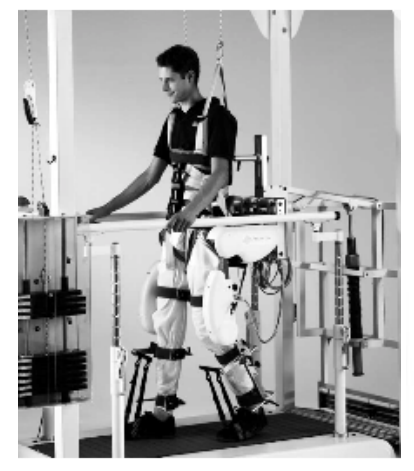

a)

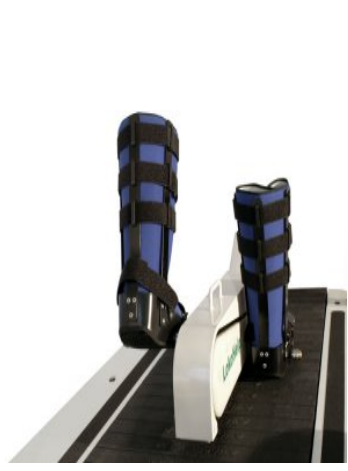

b)

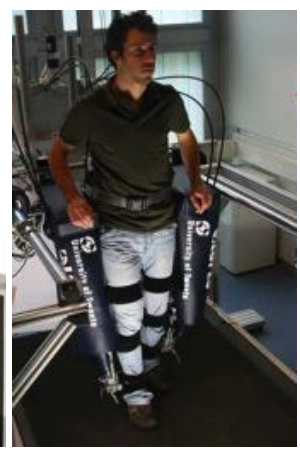

c)

Figure 3 - Robotic mobility-training devices: a) Lokomat [22], b) LokoHelp [26], c) LOPES [27].

The ambulatory-training devices are quite similar to the treadmill-training devices, but do not use the treadmill. Comparatively the ambulatory training devices propose an over ground training that can be as effective as training over a treadmill, with the advantage that requires less equipment. 
Their target users are patients, which suffer from musculoskeletal or neurological disorders (muscular dystrophy, amputee, multiple sclerosis, spinal cord injury, lower extremity joint pain). One of the most debilitating aspects for musculoskeletal or neurological disorders is the loss of the ability to ambulate [28].

Ambulatory devices explore the ability of the device to provide dynamic assistance in order to facilitate the movement of the patient, so that the patient can learn to walk with proper upright posture. On the literature, there are examples like the LiteGait [29], Walkaround [30], WalkTrainer [31], KineAssist [32], Where-I and Where-II [33] (Figure 4) and Standimovi (Figure 5).

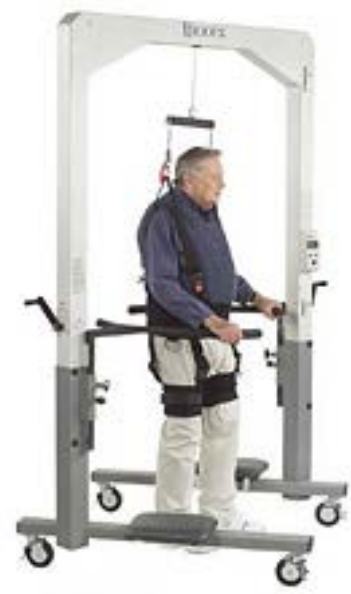

a)

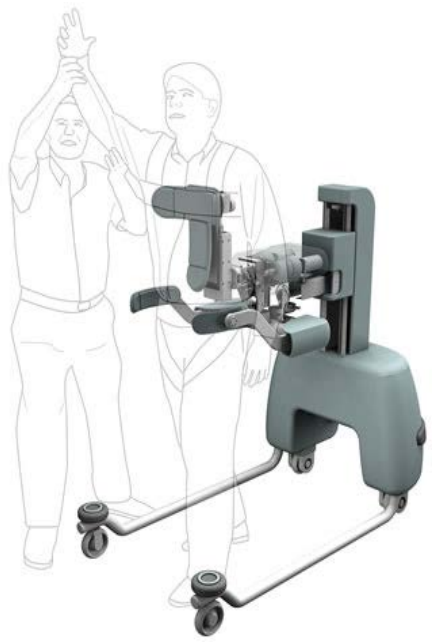

b)

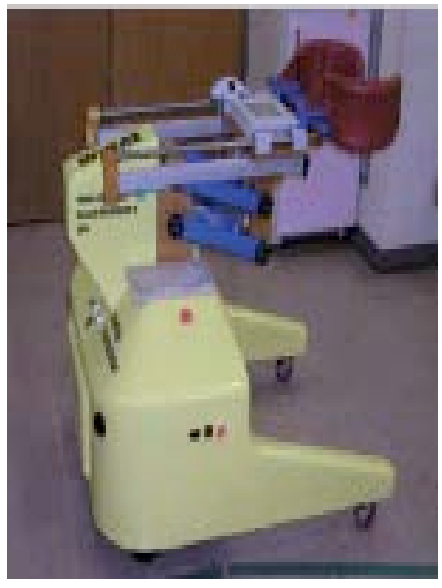

c)

Figure 4 - Ambulatory-traning devices : a) LiteGait [34], b) KineAssist [32], c) Where-I [33]

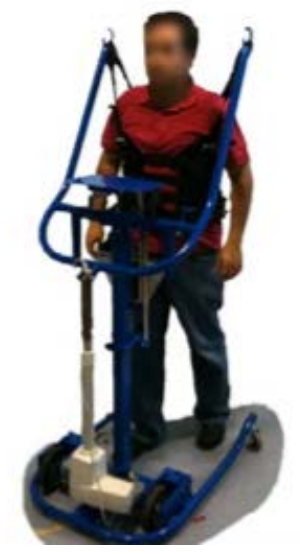

Figure 5 - Standimovi mechanism. 
Finally, the third type of devices are the feet-manipulator training devices, which are based on holding the patient's feet to a robotic manipulator. This manipulator supports and gently leads the patients in the continuous practice of walking situations. The wheelchair-bound patient is attached to a steel frame in a type of harness, their feet on plates whose trajectories can be fully programmed and imitate everyday walking situations: walking on a level, tripping, slipping or climbing up and down stairs. Reacquiring these abilities is essential for mobility in everyday life. The objective is to copy these movements as naturally as possible. As a result of these artificial feet movements the slack muscles between the toes and the hips are forced into action again.

These devices address patients who have neurological disorders. In the literature we have examples like the GaitTrainer [35] and the HapticWalker [35] (Figure 6).

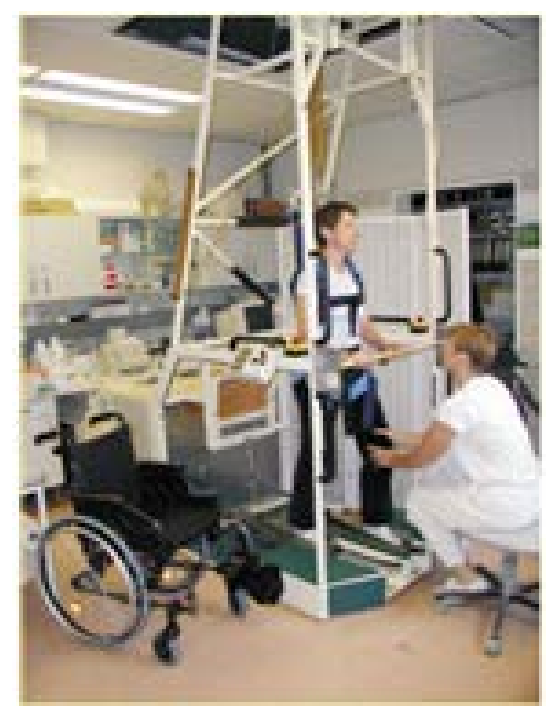

a)

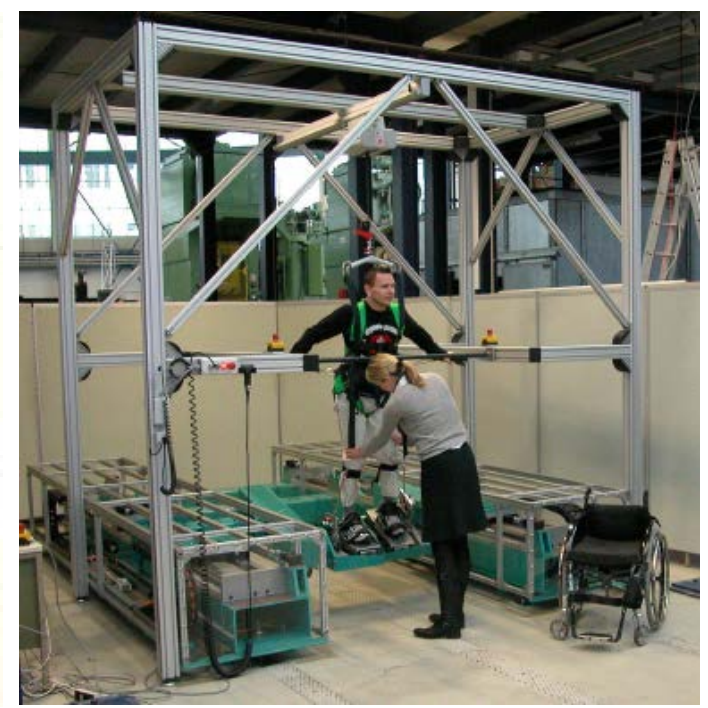

b)

Figure 6 - a) GaitTrainer [35], b) HapticWalker [35] .

The described devices manipulate the legs, according to the kinematics provided by each mechanism and the speed desired. However, they need to be permanently installed in a room. They require that patients have to be moved from their beds to that room to experience the robotic rehabilitation. Unfortunately, depending on the healthy state of the patients, it may not always be possible to move the patient out of his bed to start the rehabilitation therapy. Additionally, 
waiting may imply destruction of cortical tissues, and less possibilities of recovering these neural functionalities [36].

To overcome the above-mentioned limitations, it was designed the NEUROBike [36] presented in Figure 7. The NEUROBike system is a robotic device dedicated to the recovery of walking skills in stroke patients during the acute phase, when they are on bed, not yet able to keep a safe upright posture and walking. The system has been designed in order to provide, as soon as possible, rehabilitation therapy, thus avoiding as much as possible further damages of the cortical tissues due to their non-use [37], and to facilitate neural function recovery with repetitive exercise.

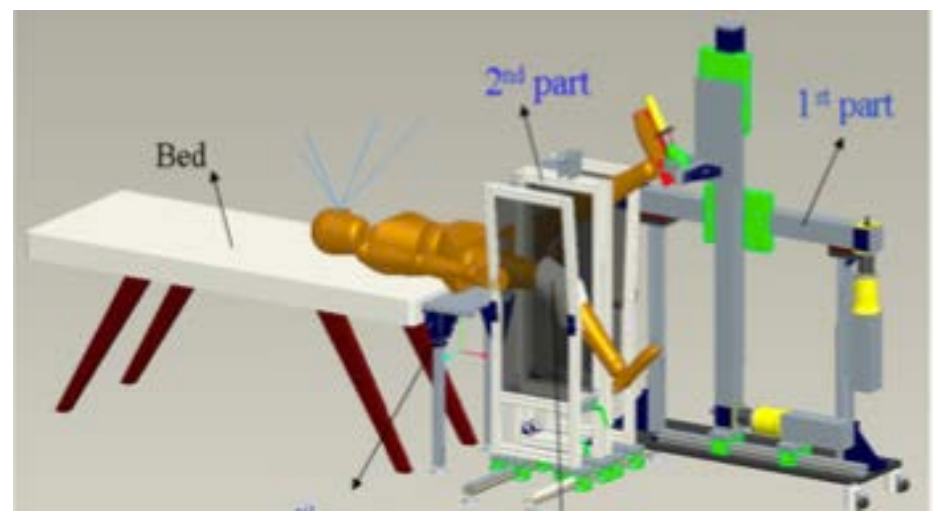

Figure 7 - NEUROBike [36].

Currently there are no sufficient and clear evidence to support a finding about the effectiveness of the training assisted by robots in people with spinal cord injuries. This is due to a low number of samples, methodological flaws, and procedures for heterogeneous training.

Unfortunately, clinical implementation of mobility-training devices remains limited secondary to the physical demands required of therapists.

Further, recently developed mobility-training devices are costly and may be less effective than therapist-assisted training. A solution to providing an economical and effective means to facilitate locomotor training in the clinical setting to increase stepping practice has yet to be achieved.

It seems clear however that a proper and intensive training can lead to real improvement and also, that only robot can thoroughly and continuously monitor patients in their daily life. For all this, rehabilitation robotics is for sure a fertile 
field that requires intensive research since there is still a long way to go before achieving the required flexibility, reliability, portability and cost.

\subsection{Self-ported devices}

Self-ported devices are carried by the user either to improve function of movable parts of the body (orthoses) or to substitute a lost member (prostheses) [38]. Between these two, orthoses are the ones that present an intense physical and cognitive interaction with the user, and are intended to offset the loss of mechanical function and work together with the movements of the patient. Orthoses allow the patient to perform a wide range of locomotor tasks on the ground, compared with the other mobility-training devices. Their function is to mechanically compensate or enhance functionally of the damaged member, acting in parallel with it [39].

These devices are intended to restore mobility to people with severe walking impairments. By enabling wheelchair users to stand, walk, and climb stairs, these devices deliver dignity, health, inclusion, and self-esteem.

Orthoses can be active or passive. Active orthoses bring the necessary energy to enable the movement by applying actuators or motors. This type of orthoses use actuators or motors. For a detailed survey verify work of AM Dollar [38] and [51]. As examples we have the HAL-5 (Hybrid Assistive Limb) [40], ReWalk ${ }^{\mathrm{TM}}$ [41], RoboKnee [42], MIT active AFO (ankle-foot orthoses) [43], MIT active anklefoot orthoses [44] (Figure 8), and GAIT [45]. 


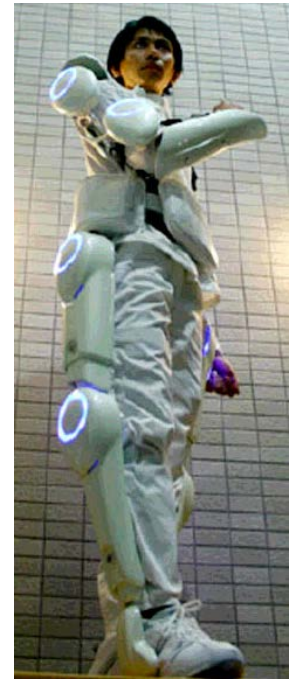

a)

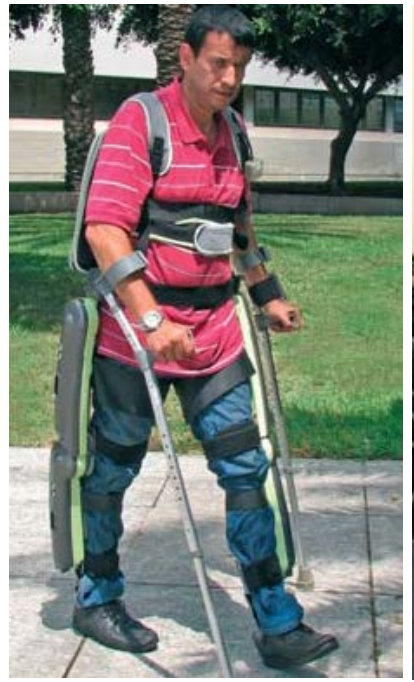

b)

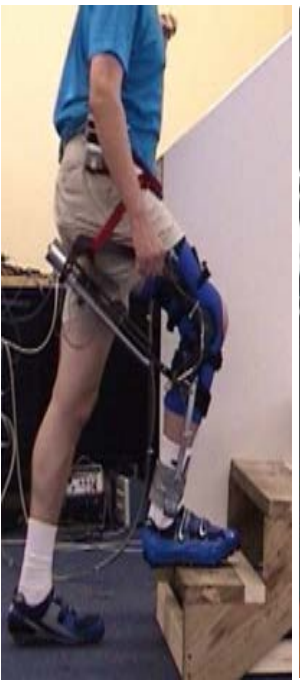

c)

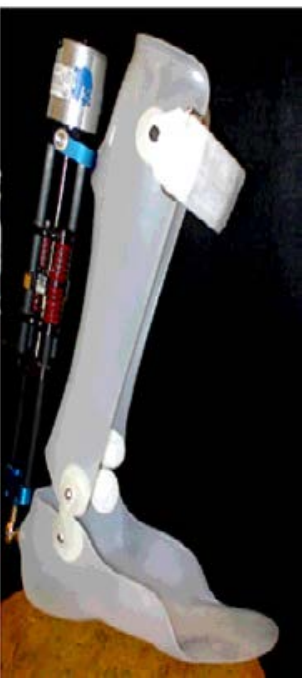

d)

Figure 8 - Self-ported devices: Orthoses a)HAL-5 exoskeleton [40], b) ReWalk ${ }^{\text {TM }}$ [41], c) RoboKnee [42], d) MIT active ankle-foot orthoses[44].

Passive orthoses (Figure 9) do not provide energy, and remain passive. Energy is provided by the user. These devices only use springs and links and are based on the Gravity-Balancing principle [46]. This principle takes advantage from the gravity force to balance the gait of the patient.
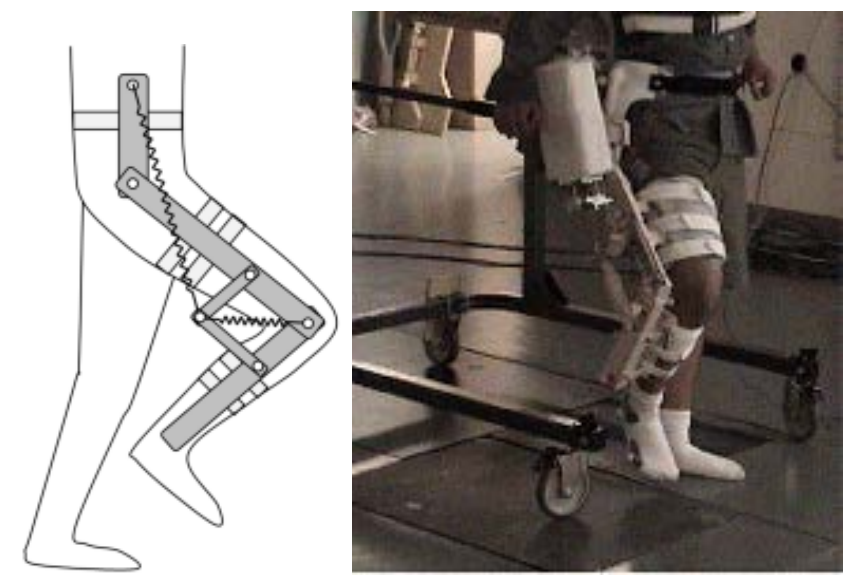

Figure 9 - Passive Orthoses based in the Gravity-Balancing Principle [46].

\subsection{External}

Canes, crutches and walkers represent the external devices. These devices are indicated to help users with balance problems and for partial weight-support.

Canes are more commonly used to increase the gait stability than to partial 
weight-support. A simple single point cane may prevent or reduce falls in patients with imbalance. An example is the standard cane [47](Figure 10a)). However, it does not seem to help falls due to retropulsion. So, there are canes that can provide greater support, like the multi-feet cane [47] (Figure 10b)).

Crutches (Figure 10c)) are orthopaedic devices that allow a direct support of the body thus providing great stability and balance in walking and a greater weight support compared with the canes. However, the crutches are cumbersome and are increasingly out of favor because they provide an unnatural gait.

As robotic examples of canes, we can find the SmartCane [48] and the GuideCane [49] (Figure 10d) and 10e)).

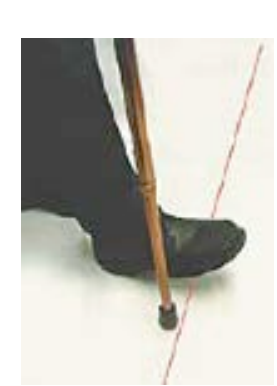

a)

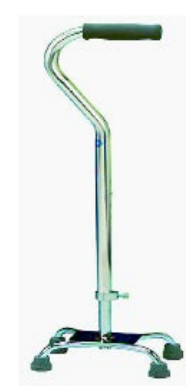

b)

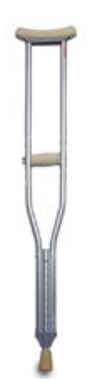

c)

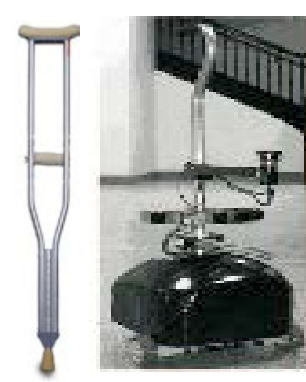

d)

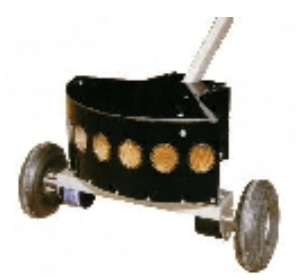

e)

Figure 10 - External Devices: a) Standard Canes [59], b) Multi-feet cane [10], c) Crutches [50], d) SmartCane [48] and e) GuideCane [49]

The SmartCane, developed in the Massachusetts Institute of Technology, is a very well accepted device that helps to guide and support the user. It uses a pair of three-dimensional force sensors to measure the applied efforts of a user on a cane integrated on a mobile robot. These inputs are transformed in velocity and direction information. It also detects obstacles so that the user can avoid them.

The GuideCane is exclusively to guide visual impaired users and then help them to avoid obstacles using ultrasound sensors and GPS. The user indicates the desired direction through the movement of a joystick.

Finally, walkers are the devices from this group that provide greater support. They can have feet or wheels and are pushed by the user using hands or the forearms to guide the device. As this work is devoted to the study of these specific devices, it will be presented, on the following section, a detailed critical review about the walkers. 


\section{Walkers}

Walkers assume an important role due to its simplicity and rehabilitation potential. These devices are interesting once they work as a supporting device during bipedestation and, in addition, use the person's own remaining locomotion capability in order to move [5] avoiding the early and deteriorative use of wheelchairs.

Walkers are prescribed to improve patients' mobility and help them maintain balance [10][56]. These devices can increase confidence and sense of safety, which can raise a patient's level of activity and independence. There may be physiological benefits of limiting osteoporosis, reducing cardiopulmonary deconditioning and improving peripheral circulation [10].

Static equilibrium is maintained when the body's center of mass is positioned over the base of support. Loss of balance can result when the center of mass is displaced in relation to the base of support because of voluntary movements or external perturbations, such as slips, trips or pushes. Use of a walker increases the base of support, thereby allowing a greater tolerated range for center of mass positions [66]. They can also prevent instability by allowing stabilizing reaction forces such as holding on or pushing against the ground [10].

There are many types of walkers, considering their constitutive materials, accessories, sizes and structural configurations. These are classified in two types: conventional and Smart walkers, detailed described on the following.

\subsection{Conventional Walkers}

An important aspect that classifies conventional walkers is the ground contact configuration, so they are classified by its type of support with the ground [55]: Standard, Front-wheeled and Rollators. 


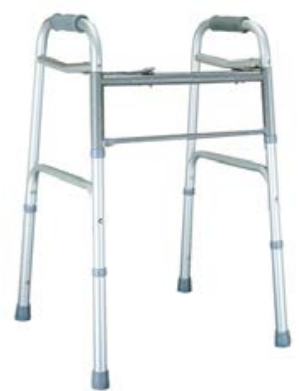

a)

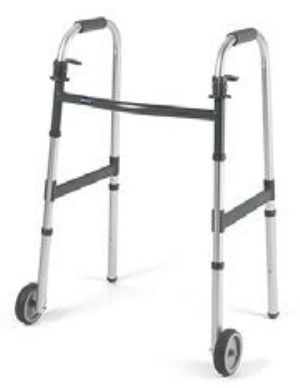

b)

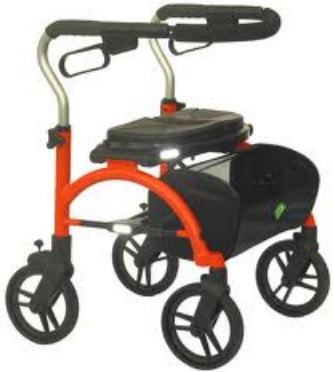

c)

Figure 11 - Conventional Walkers: a) Standard walker [55], b) Front-wheeled walker [55] and c) Rollator [10].

The Standard walker (Figure 11 a)) is a metal, four-legged frame with rubber tips, which must be lifted and moved forward while walking. This type of walker is used when maximum assistance with balance is required or when restrictions on weight bearing are present. While easier to use than a cane, this type of walker does require some degree of upper body strength and cognitive ability to use safely, and results in a fairly abnormal gait [51]. This device has also little value for retropulsion (many patients fall over backwards still holding their walker) and propulsion [10].

The Front-wheeled walker (Figure $11 \mathrm{~b}$ )) is designed for people who have weaker upper-limbs or that tend to fall backwards when lifting the device. This type of walker promotes a forward displacement of the center of gravity and allows a more normal gait, as the person can continue walking without stopping to lift the walker. It is particularly useful in patients with Parkinson's disease, as it reduces the risk of falling backwards. Cubo et al. [54] studied Parkinson patients who had gait freezing with objective measures and found that although standard walkers may stabilize patients and may increase confidence, walking speed actually slowed when using a walker. In this study, the standard walker increased freezing and the wheeled walker had no effect on freezing. In addition, it is less likely to allow the patient to pick up speed as he goes along, relatively to the fourwheeled walker [5].

Rollators (four-wheeled) are the easiest to use of the three types, but also provide the least stability. Studies [10] show that most patients now prefer these compared to the other conventional walkers (Figure $11 \mathrm{c}$ )). They do not need to be picked up, but have modern wheel systems so they roll and pivot smoothly and with little effort. They promote the most natural gait patterns. Wheeled walkers for 
use in the community can be equipped with baskets for shopping, and a seat that allows the person to stop and rest, if required [51]. Hand brakes can be selected to stop the device when squeezed or when released [10]. However, the user must be capable of learning to apply the brakes in order to use them safely [5]. Another option is the presence of a padded bar across the front that initiates braking if the patient presses or falls onto it. This bar is useful for patients with poor grip strength, speed or dexterity [10].

For example, Boomer [52], presented in Figure 12, was designed by Daniel Molloy, Australia, and has a futuristic aesthetic. It allows the user to climb stairs: by pushing a bottom the front wheels can move along to near the back wheels so that it becomes a kind of cane that helps in the up and down of the stairs. The user can support his weight on the structure safely, because the wheels are locked and have a linear motion from top to bottom in order to help to climb the stairs.

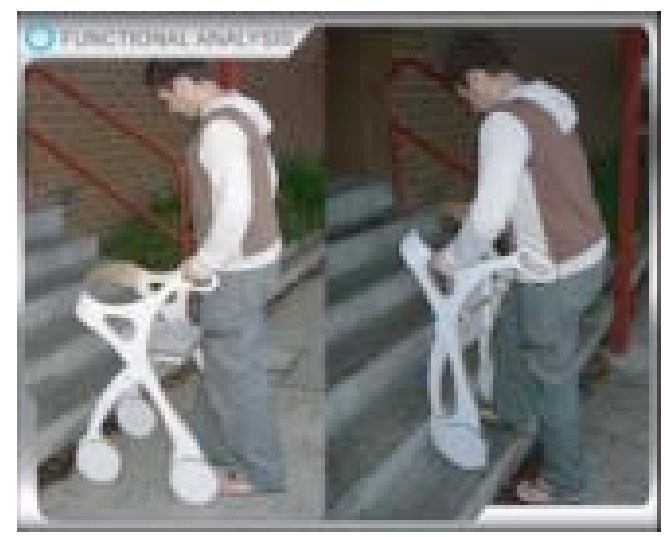

Figure 12 - Climbing the stairs with Boomer [52].

Another example is the U-Step walking stabilizer [53][54], of the In-Step Mobility (Figure 13). Its velocity can be adjusted through crank, as well as the height. Its structure can have also a compact form (Figure 14). 

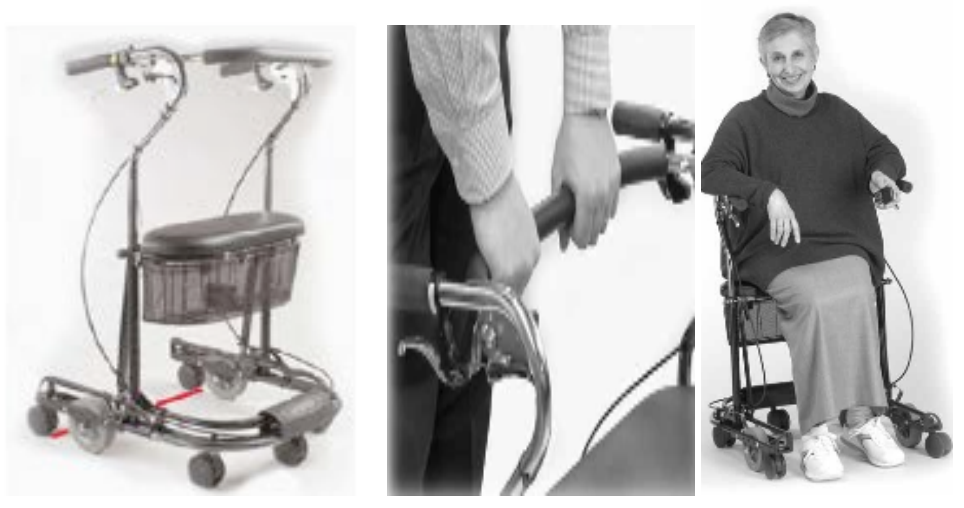

Figure 13 - U-Step walking stabilizer [53].
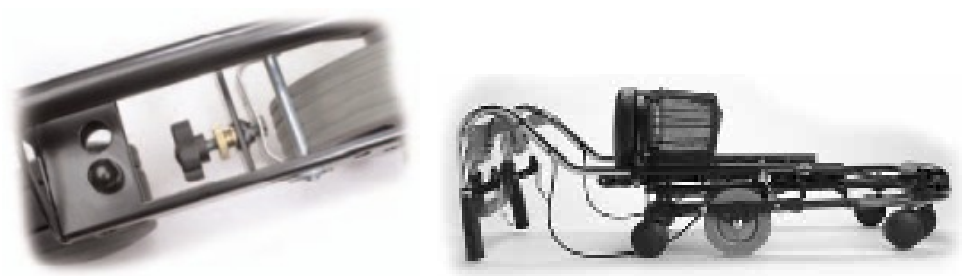

Figure 14 - Adjustment system of velocity and compactation of the U-Step Walker [53].

Despite potential benefits, looking at a variety of conditions in which assistive devices are prescribed, studies have shown that $30-50 \%$ of people abandon their devices soon after receiving them [67]. These findings raise questions about effectiveness, proper selection, appropriate training and potential problems.

Some reports have pointed out that walkers may actually increase the risk of falling by a variety of mechanisms [68][56]. A walker can potentially cause a patient to trip if it catches their foot. Similarly, a trip or fall might be precipitated by a device "catching" objects in the environment such as carpets, furniture or doorframes [69]. An unexpected perturbation of balance might occur if the device slips or tips over [69]. In these circumstances, preventing a fall may became more difficult for patients that suffer from potential instability, as Parkinson patients for instance.

Actual devices require the patients to allocate adequate cognitive and attention resources to control an assistive device [56]. This may be challenging for patients 
with executive dysfunction, which impairs the ability to engage in more than one activity at a time and to switch attention and tasks, or dementia [10].

Other disadvantages of walkers include the need of more space in which to maneuver comparatively to a cane; difficulties on rolling on carpeting, and difficulties in crossing obstacles. The use of any walking aid, in particular walkers, results in a slower gait speed and requires considerably more energy and cardiovascular fitness than walking unassisted. In this context, the assistance during the gait process is a clear application on the assistive robotic field [57].

\subsection{Smart Walkers}

Smart walkers have emerged with the same structure as the conventional ones but they include additional robotic and electronic components, that promote a better assistance to gait, especially considering navigation [58], gait monitoring [59], and partial body weight support [59] [60]. However, some of these devices became too complex to use. When designing a walker, it is needed to take into account not only the users' disabilities in locomotion but also the fact that many of these users have additional deficiencies at cognitive and sensory levels. For instance, elderly people usually present slower behavior and are not familiar with mechatronic devices. Further, walkers should be designed to continually evaluate and correct their actions based on their perception of the needs of the user. Also, the walkers need to be used during the daily routines of the user, such as, go to the bathroom, elevator, etc. Therefore, they have to be completely accepted by the user in their daily life.

In summary, Smart walkers have to take into account usability issues, such as, safety, comfort and simplicity of use of the device. The development and evolution of technologies enabled to integrate a range of useful features to the smart walker, so these become easier to command and more comfortable to the user.

In the overall, smart walkers have evolved to provide assistance to the user at different levels, depending on the user's needs. Generally, they can present the following functionalities [61]: i) Physical support; ii) Sensorial assistance; iii) Cognitive assistance; iv) Health monitoring and v) Advanced human-machine interface. This last functionality was proposed within this work. 
In the following subsections these functionalities are presented along with a critical review regarding the most relevant smart walkers existing in the literature.

\subsubsection{Physical support}

Almost the totality of the smart walkers present among their features some kind of physical support functionality to provide a better gait stability to the user. There are mainly two types of physical assistance: passive and active.

Passive physical support functionality introduces mechanical or structural enhancements to the device improving stability during gait. Usually, the improvements performed consist on the enlargement of the base of the device or the balanced placement of heavy elements (motors, batteries, electronics, etc.) at lower planes of the walker increasing the dynamic stability. Other passive change, not as commonly observed as these last ones is the replacement of the conventional handlebars of the walker by forearm support platforms [61][63]. For instance, the Mobil walker [64] (Figure 15) was designed to offer more support assistance through the platform that supports the forearms, and additional help to the user when he is standing up or down.

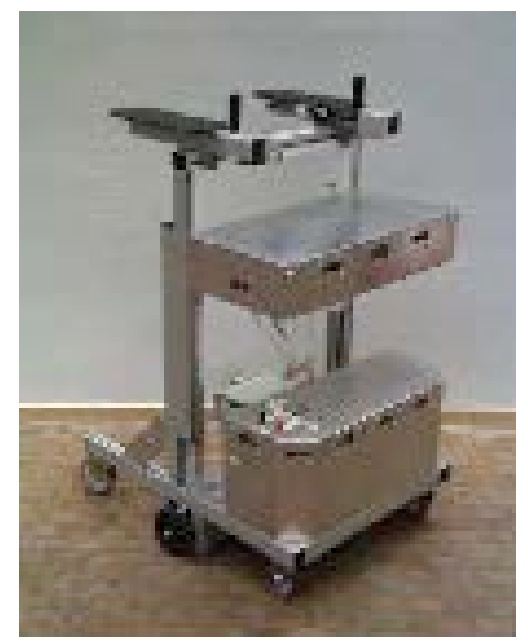

Figure 15 - Smart Walker Mobil [64]

The ASAS [63] and SIMBIOSIS [65] smart walkers have also used forearm support platforms and tested them clinically with elderly and injured spinal cord users. The tests showed that these supports eliminate the degree of freedom of the elbow articulation and a higher fraction of the user's weight is supported by the 
device, making it easier to push and increasing the friction component of the system, reducing the risks of glide.

Other possible enhancement concerning the reduction of gliding with the ground is the selection of materials with high coefficient of friction for the walker wheels.

Considering the walkers with three or four wheels, a common problem is the control of the device's free motion. More specifically, these devices have usually a brake system similar to the one installed on bicycles. Therefore, breaking a conventional walker is a task that requires muscular strength, motor coordination and good reaction time from the user. If any of the before human faculties fail, there is a risk of an excessive acceleration of the device and a consequent fall. In addition to the breaking problems, it is important to emphasize that both the strength and coordination are necessary to push/guide the walker and their demand can be high, thus difficult depending on the degree of disability of the user. In this case, it is important to provide external and controlled pushing energy to the system.

To prevent such situations active physical support functionalities are explored in several Smart walkers [65][70][72]. Usually, motors are installed on these devices wheels to control the brakes [70], to compensate gravity on inclined grounds [72] and to provide the pushing energy necessary to move the device [65][71]. Different Smart Walkers explore different solutions to control wheels direction and velocity.

An example is the PAM-AID walker (Personal Adaptive Mobility AID) [70][71], presented in Figure 16, which aims to provide to the user the maximum control of the device during the entire time of its use in a more practical way. The controller of the PAM-AID just acts on the front wheels to control the direction of the device and it is composed by a handlebar that can rotate $+/-15^{\circ}$ on the vertical axis. Besides, this walker has two operating modes: manual mode, in which the control of the device is done only by the user, and assistive mode, in which the system controls the front wheels to avoid obstacles. 


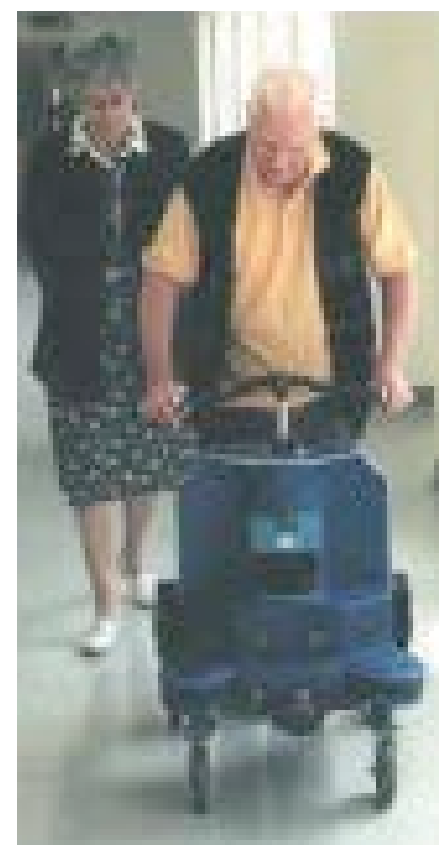

Figure 16 - PAM-AID walker [70]

An improvement is the iWalker [72] (Figure 17), that incorporates inclinometers on its system that can detect if the surface is inclined or not. This information enables the walker to increase or decrease its velocity depending if it is an up or down slope. The goal is to adjust the robot velocity while climbing. This will help the user to walk in slopes, a type of terrain that usually leads to the fall of the user.

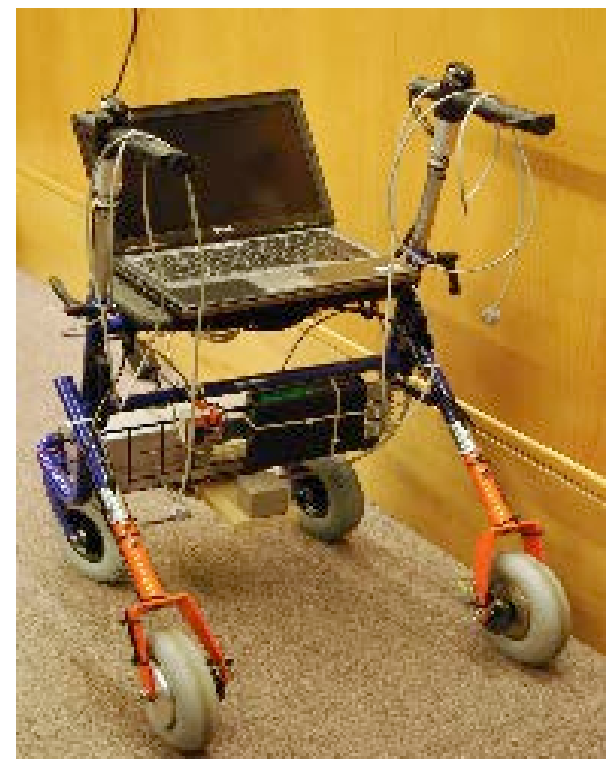

Figure 17 - i-walker [72] 


\subsubsection{Sensorial assistance}

The smart walkers may also provide sensorial assistance to the user, according to navigational and security issues.

Early obstacle detection is extremely important for people who use walkers. Due to the effects of impaired balance, sudden changes in terrain can sometimes present serious challenges to balance, even when one is using an ambulatory aid.

Normally, the navigation and obstacles detection employ ultrasonic, vision or infrared sensors capable of detecting static and dynamic obstacles. The control system assists the user in obstacle avoidance by sound or vibration alerts or operating directly on the device's actuators, momentarily changing the path introduced by the user. This function is usually designed to help users with visual problems or to help navigation on environments with multiple obstacles.

The PAM-AID [70] (Figure 16) aims to guide blind people and is equipped with three types of sensors that are used to provide information of the surrounding environment: sonar (navigation and collision avoidance), infrared proximity sensors (proximity detection) and bumper switches (collision detection). The information obtained by the environment is given to the user in the form of voice messages that describe the surrounding and warn about the emergence of obstacles. The data gathered is sufficient for obstacle avoidance and is simple enough to allow rapid processing. Another functionality is that the device can detect descending stairs, not dragging the user after it.

Similarly, the MARC Smart walker [73] includes a forward bumper and laser/infrared sensors to indicate the presence of an obstacle or stairs in the user's path.

An improvement of these two walkers, in terms of navigation, is the Nomad XR4000 mobile robot platform [58]. This walker is equipped with two circular arrays of Polaroid ultrasonic transducers, two circular arrays of Nomadics infrared near-range sensors, three large touch-sensitive doors, and a laser range finder. These sensors enable the system to perceive obstacles at various heights and the laser range finder is used for navigation, and it is also possible to do path planning.

However, none of these systems address the risks of falls or other mishaps that could happen while the user is guiding the walker, or when the walker stops. They just evaluate the state of the environment and forget that the space area where the 
user is walking is also important to be aware of. So, it is necessary to develop subsystems that are alert to the situations of danger in that space. For this reason, the walker must have the capability to predict and avoid falls or similar situations that involve risks to the user and, then, stop, and avoid the possibility that the walker may roll away from the user while walking. This is possible with the use of sensors that evaluate the distance of the patient relatively to the walker, like it has been done in the ASBGo walker [91]. In this study, a sensing system, using infrared sensors that measure how far the user is from the walker, detecting dangerous situations such as falls. Beyond these, it was created a system with contact sensors on the handlebars that make sure the user is effectively guiding the walker with the two hands.

\subsubsection{Cognitive assistance}

Smart walker can also be classified according to their capability to assist user navigation and (auto-) localization in structured environments and outdoors (using GPS, for example). These smart walkers are very important to people that have cognitive issues and problems related to memory and orientation. Some smart walkers [72][58] are programmed to follow predetermined paths inside clinical environment or to achieve a certain location in a map of a house or medical facility. Other devices are capable of creating maps of an unknown environment or localization in a map using markers placed on the surroundings.

Smart walkers may also be able to communicate bidirectionally with the user through a visual interface or voice commands, receiving directions from the user, or informing him about the present localization in a map and the environment conditions, e.g. obstacles.

The iWalker [72] (Figure 17), for example, has a navigation service that disposes to the user a map of the environment and their localization on it. They can ask for a route to reach some destination and real time indications to follow it. If navigation is interrupted by non-avoidable obstacles, the system can suggest a new route or offer to ask for help to a caregiver. 


\subsubsection{Health Monitoring}

In more specific situations, the smart walkers can be used to monitor some health parameters of the user. This health information is used to keep a medical history of the user or inform through a wireless communication network a health center or the medical staff in case an emergency situation is detected.

The PAMM Smart Walker [74] focuses specifically on the users' needs in an eldercare facility (Figure 18). It provides greater support for walking; monitors the health of the user (e.g. electrocardiogram), and it informs the user about his scheduled of tasks (e.g. taking medications). These functions were developed so that the elderly people can live more independently.

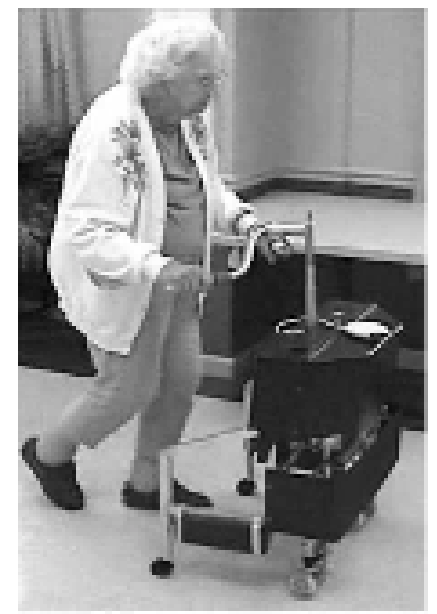

Figure 18 - PAMM Smart Walker [74].

\subsubsection{Advanced Human-Machine interface}

Systems and machines have increasingly evolved in capacity and functionalities, so now they can assist humans in tasks of higher level of abstraction. The elements that establish a bridge of interaction between human and machine, called interfaces, must establish a dialogue between these identities as user-friendly and efficient as possible [76].

The interface should be able to adapt to users with different levels of physical and cognitive capabilities and this adaptation should be done in a user-friendly manner. 
In interfaces, the role of the sensors is very important since they measure the environment and human interaction and transmit the information to the device so that it can accomplish the task that is being demanded by the user [77].

The Smart walkers can present two different kinds of interface: direct interface in which the user commands or the user intentions can pass directly to the device; and indirect interface if otherwise.

One example of a direct interface is the joystick. Hashimoto et al. [78] developed a walker that is driven by a direct manipulation of a joystick (Figure 19). This joystick besides transmitting to the motors the user's intention of direction, it has a user-friendly hand force feedback system that allows the user to perceive obstacles and thus walk with greater safety. According to a repulsive force from the joystick, the user can know the distance and direction to the obstacles.

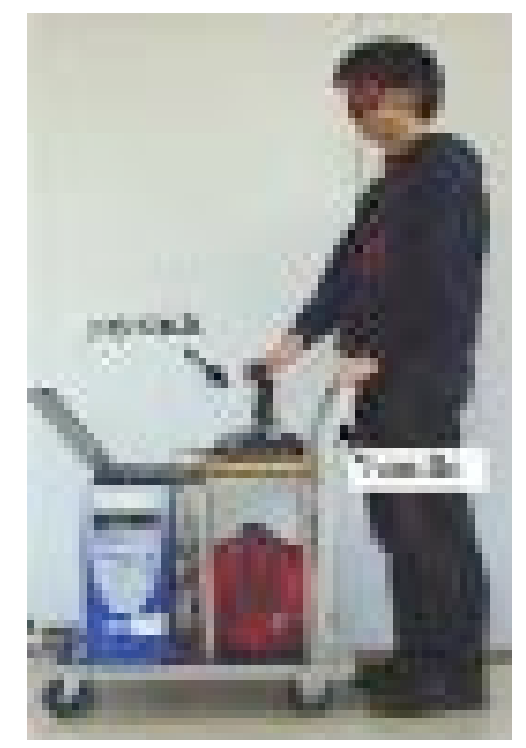

Figure 19 - Walker with a joystick as an interface [78].

Force sensors have also been the focus of direct interfaces, because by detecting the user's intentions through physical interaction, the force sensor interface offers a user-friendly and intuitively way to reach that goal.

Handlebars are usually employed to provide for the support and stability in ambulatory devices. They require the user's hands to grip firmly. Morris et al. [58] developed a robotic walker based on the XR4000 platform with two-force sensors embedded into the handlebars. The idea is that by incorporating force sensors 
inside the handlebars, the user can maintain a steady hold and manipulate the robotic walker in a manner more consistent with contemporary roller-based walkers.

Another way to integrate the force sensors in the handlebars is presented by the latest version of PAM-AID, Guido [79]. It is guided by the user with springloaded handlebars, which are equipped with sensors to determine the intended direction of travel (Figure 20). Turn buttons are located on the end of each handlebar. Pressing these buttons causes the front wheels to turn parallel to each other in the same direction and thus allows the walker to rotate in a circle about its rear wheels. Brake levers are also positioned on the handlebars. If the user squeezes the brakes, the front wheels will both turn inward to stop the walker.

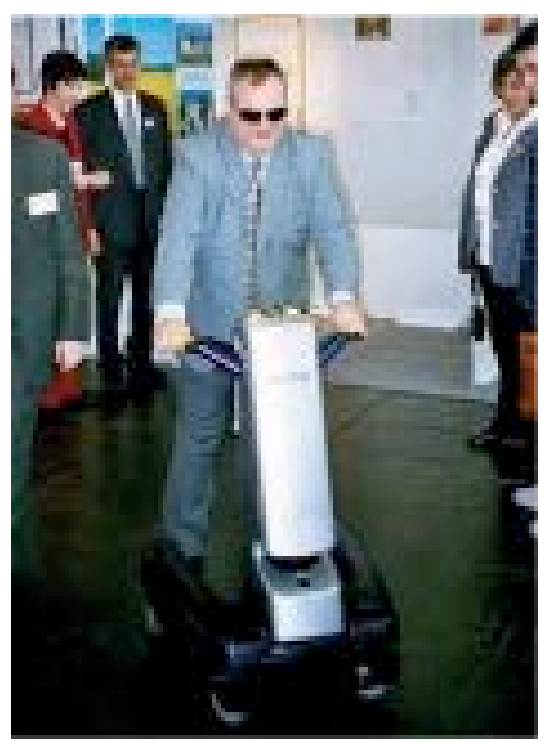

Figure 20 Guido Walker [79]

Another example is the Walkmate [80] that has two force sensing resistors embedded into the handlebar (Figure 21). These sensors are fixed with the handlebar directly so it can detect both pull and push pressure of the handlebar. Moreover, the force sensors embedded into the handlebars offer a natural negative feedback loop of the motion control. When the user wants to keep a constant velocity, the handle will be pulled/pushed to decelerate/accelerate the walker if the walker is faster/slower than the user. 


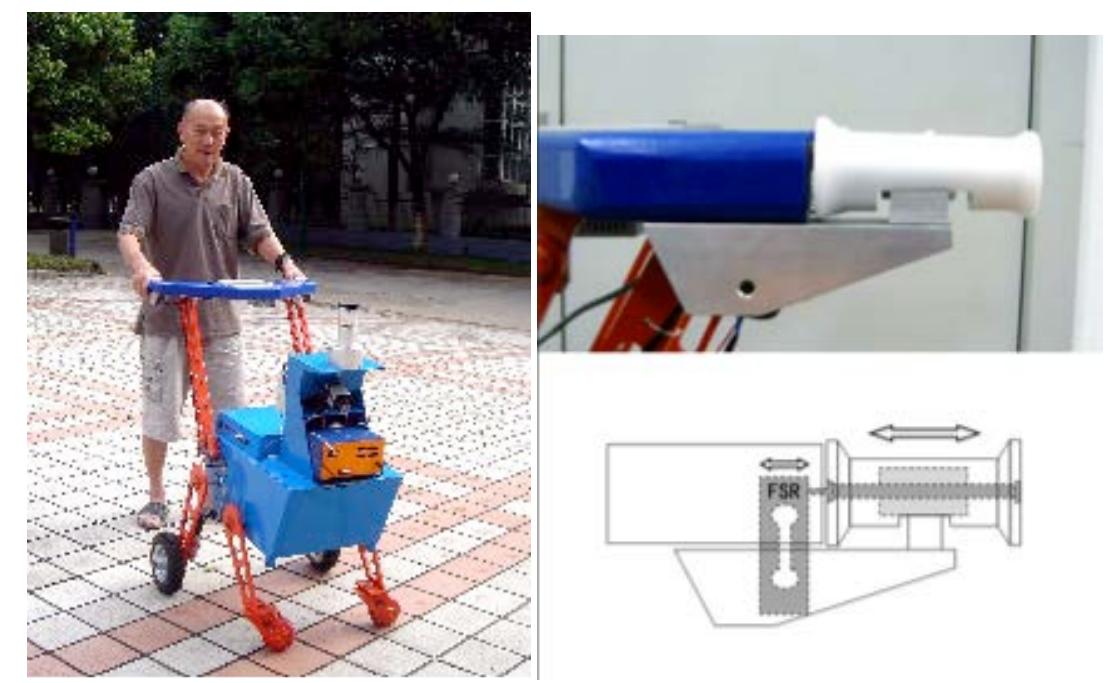

Figure 21 - The Walkmate and its handle-bars as a force interface [80].

A recent development is the SIMBIOSIS [65]. This walker presents a multisensory biomechanical platform for predictive human-machine cooperation. One of the sensory subsystems is the force interaction that is compound by a set of force sensors installed on the walker's forearm-supporting platform. The forces that are applied by the user on each forearm-support while he his walking are measured and the guidance information can be inferred. This turn out to be a natural and transparent interface that did not need previous training by the user.

Other works addressing interfaces with force sensors are UTS [82], Chuy et al. [83], MARC [73], ZJU walker [81] and Sprint [89].

The evaluation and conclusion of which type force sensors integration is the best one to use as an interface is yet to be investigated.

Another kind of direct interfaces is the voice communication. To help the visually impaired, for example, it was developed by Gharieb at King Saud University [84] a walker that has the ability to avoid obstacles and steer by following the user's voice. The walker receives the voice command from the user and determines the required tasks. If the speed of the walker exceeds a maximum limit value an audio alarm will be activated, and when there is an obstacle it warns the user with an audio alarm, too.

On the other hand, indirect interfaces have to recognize user's movement and/or intent without requiring manual operations. Examples include visual recognition using cameras [85], and detection of human gait using pressure sensors [86] and ultrasonic sensors [61]. 
A recent prototype of a walker is the JAIST active robotic walker (JARow) [85][92], which was developed to provide to the users the opportunity to recover from their disabilities in an efficient and economical way (Figure 22). The development of this walker took into account that elderly people have a very slow performance, and are not familiar with electronic and mechanical controls. Thus, the prototype JARow applies a pair of infrared sensors [85], and later with laser range finders [92] on the lower base of the walker to control the rotating speed of the motors. These sensors detect the position of the lower limbs of the user, which is used to calculate which direction and speed the walker must perform to follow the user.
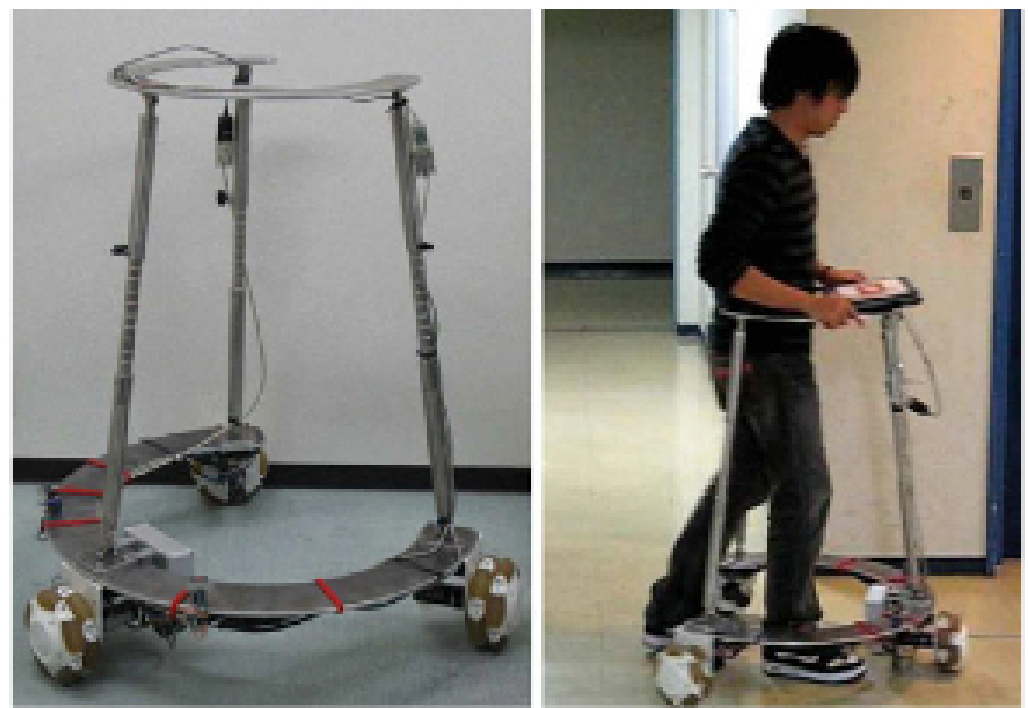

Figure 22 - Prototype of the JAIST active robotic walker (JaROW) [85].

Research has mainly focus on developing direct interfaces with force/torque sensors, because unlike the joysticks, buttons and switches, for example, the force sensors are more robust, precise, and intuitive and provide better information. For instance, when the joystick is moved in any direction during the gait, due to the foot strike or uneven terrain, vibrations may appear.

Relatively to the buttons, switches and touch screens, they might be simpler and easy to control, but they have an intermittent or discrete operation that is mentally heavy for the user. Moreover, these interfaces may cause confusion for elderly users, which might result in an accident. The voice communication, for example, has an advantage of transferring effective high-level commands as a 
bilateral communication tool. However, there are critical problems such as interference and recognition yet to be resolved.

Indirect interfaces have strong demands on visual recognition, and to achieve progresses, it requires complex recognition algorithms with high computational costs and high performance devices.

Another problem is the human gait detection. Normally, these interfaces use ultrasonic or infrared sensors. In some cases, ultrasonic sensors require the user to worn an additional device on the human body, which is a major disadvantage. Interfaces based on infrared sensors such as in the JaRoW prototype, besides being sophisticated, still have several issues to be resolved. For instance: the human gait control system is nonlinear; the gait parameters vary across users; the gait of users with disabilities is slow and irregular, and the sensors can mix the legs causing the controller to make wrong decisions about the intentions of the user.

Recent studies on walker interfaces [78-88] have not focused on the characterization of the signals gathered by the interface sensors, and it is currently lacking an exhaustive analysis of the main parameters involved in the interaction between the user and the device. It is required to identify these parameters and their connection to the subsequent algorithms used for detection, attenuation, recognition and estimation. Different approaches may lead to a better manoeuvrability of the walker. The intentions of the subject on the guidance of the walker were inferred in previous work [61] by using algorithms to effectively estimate the cadence and significantly attenuate or eliminate the components of the force signals related to the oscillations of the trunk. . The approaches can be based on applying fuzzy control [65], model based-approaches [80] [89], probabilistic models [75] and others.

The Walkmate [80], for example, has two force sensors that detect both pull and pressure of the handlebar (Figure 22b). These pressure signals are then sent to the computer to calculate the output to the motor control board. The velocity of the robot and the acceleration are set proportional to the force applied to the force sensor interface in the handlebars, which mean the robot will run or stop instantaneously when the user's hands hold or leave the handlebars, respectively. However, this algorithm does not provide great stability to the guidance of the walker. 
Another walker [82] that is being developed at the University of Technology, Sydney, takes two user intent variables from its force sensors: travel speed and turn rate. To measure user intent, two strain gauges have been placed on each handlebar of the walker based on FEM (Finite Element Method) analysis. Outputs from the individual circuits on each handlebar are combined to determine the user intent. The sum of the outputs gives the forward or backward moment on the handlebars and the difference gives the left or right turning force.

Another study [83] implements a control motion based on an applied force by the user that is passed to an apparent dynamics to determine the desired state of the system (velocity and position). Each desired wheel velocity is determined based on the inverse kinematic equation of the system. This implementation has shown to be instable to the system, so it requires a better evaluation of the control algorithm that uses the user's intentions to avoid instability. Model-based approaches require having a precise model of the walker, user and the surround environment and thus are prone to errors and have difficulty to adapt to variations, which are essential in real time applications.

Other examples of control systems can be found in [60][81][87][88].

Despite the development of these various techniques to work for activity recognition, they are often limited in scope and tailored to some specific (learning) technique [75]. Additionally, there are still many unsolved questions and key areas in determining user-friendly and efficient interfaces. Further, it is very important to remember that these interfaces should not increase the cognitive burden or cause confusion and frustration to the elderly or to the lower limb disable users.

\section{Current challenges and directions}

Despite the good results that the works presented have shown some improvements should be made in terms of scientific contributions, design implementation, control algorithms and robotic methodologies. This leads to new challenges that have to be overcome.

A general concern among smart walkers is the braking system that has to be easily manipulated, intuitive and effective, to avoid dangerous situations, such as, great accelerations of the walker on descending surfaces and the fall of the user. 
Future researches should improve the safety and stability of walkers, and avoid to inadequately resort to alternative devices such as wheelchairs, that have disabling effects, thus contributing and reinforcing to the maintenance or to the improvement of the physical and cognitive capabilities of the user.

A necessary step is the improvement of a smart walker capable of supporting the weight of the user but that can be used to stably and safely drive him with a high manoeuvrability. For this purpose, different handle bar designs must be addressed and it must be verified the best way to dispose the base support of the upper limbs of the user, in order to improve the manoeuvrability of the walker and to improve the ergonomics. Additionally, it is important to understand and study the dynamic model of the walker, to quantify and ameliorate the stability of the walker, while the user is guiding it through unknown territory.

Additionally, it is necessary to find components that are low consumption and the battery system has to be improved. For safety the electrical system has to be isolated from the environment in an enclosure to prevent damage from liquidspills, etc. On the one hand, the re-charge time of the batteries should not be longer than eight hours to achieve full charge thus allowing re-charge overnight. On the other hand, the runtime of the system should be of the order of six hours. Further, the re-charge system should be simple to connect and monitor.

The studies about interaction between the walker and the user are beginning to take place on the list of concerns with the smart walkers. This is an area that needs to be more explored because the studies evaluated here lack a detailed description of the main parameters that describe the interaction between the user and the device. It is therefore a key area to characterize the signals gathered by the interface sensors, by performing an exhaustive analysis and description of the main parameters involved in the user's behaviour and in the interaction between the user and the device concerning the driving of the device according to the user's intention. It is essential to be able to anticipate the user's intentions such that the walker might proceed accordingly. Thus, one should point out that there are different assessments to be made at different points. For instance, the way the user supports over the walker is important, but also is important the way his feet move or the way his body balance or even his cardiovascular fitness. The developed sensor systems should target these different assessments and control should tackle each one of them. So, in order to improve the reading of the users' intentions it is 
required to identify the parameters involved in these signals and their connection to the subsequent algorithms used for detection, elimination, attenuation, recognition and estimation. These algorithms need also to be useful for this realtime application, since the walker must respond with the minimum delay to the user's "orders". This is a concern for the majority of the works presented here, which developed an algorithm that suits well for their objectives, but is not suitable in real-time.

Further, due to the limitations on current recognition and control algorithms and computational costs that need to be decreased, there is room for further improvements and this is being a turning point for research.

In order to act as functional compensation/rehabilitation device, the smart walker should automatically adapt to the needs of its user and lend only the required amount of support to enable this. Two steps are therefore required. Firstly, the device should continuously measure the basic physical signals of its user's movement direction, velocity, and handle-grasp force. Secondly, a study should be performed to collect the variables that need to be controlled on the walker.

It is also necessary to better understand how the connection between the user and the walker works, as well as the benefits that Smart walkers can bring to the gait, posture and motivation of the patient, to improve the achieved results on the rehabilitation process. Thus, it is needed to study posture and gait disorders which can benefit from the smart walkers' assistance. Further, it is required to understand and propose new sensorial systems able to online assess the required metrics such that control may proceed accordingly.

In these works a static approach showed very goods results, however with healthy users. The healthy users are more stable and predictive than the pathological users, that have unpredictable behaviours, are sometimes asymmetrical, etc. Thus, it is needed to provide assisted locomotion adapted to the user's needs and to short- and long-term changes in mobility capacities and modifications on gait patterns. The control of the smart walker should be transparent to the user and the filter and control strategies should be adaptive and dynamic.

Generally, the motion control algorithms are developed without taking into consideration the real interaction that happens between the user and the walker. To 
gather this knowledge it is necessary to run tests with the user using the walker without any control, and with the motors disconnected. This procedure enables to detect the signals that represent the movement intentions of the user [90] [91]. These experiments enable to collect the natural signals obtained through the interface without the interference of any control strategy, and thus to verify the real intentions of the user. This enables to develop a natural interface that does not require a learning phase or special skills to drive the walker.

These new routes require the medical staff to be intensively involved in the loop. So, contacts have to be promoted with both medical staff and clinics for medical evaluation and quantitative assessment of the walker's potential as a rehabilitation and functional compensation tool. Further, the Smart walker can be used as a diagnostic tool that will enable doctors to monitor from distance the medical conditions of their elderly patients, thus dramatically reducing clinic visits.

Most of the developed works [81-83][85-86] in this review employed uneconomic solutions, and the major were not evaluated with elder users or user with disabilities, which are in fact the target population. These points are essential to turn possible to advance towards a commercial product, and assess the target population. By this, the ASBGo project [91] and JARoW [92] intend to develop an affordable Smart Walker, with an affordable cost but high reliability and safety. The motivation is that this will contribute towards better rehabilitation purposes by promoting ambulatory daily exercises and thus extend users' independent living and improve their life quality.

\section{Conclusions}

On this article, it was made a brief review of the dysfunctions that can affect the mobility, and it was presented a critical review about the assistive mobility devices existing on the literature, giving emphases to the walkers, and more specifically the smart walkers.

The review about the walkers has shown that in the last years their development has witnessed a huge increase due to their enormous potential for rehabilitation and functional compensation. This potential emerges since this device makes use 
of the residual mobility capacities of users, maintaining and/or ameliorating them. Thus, it provides the opposite effect of the wheelchairs, which have a disability effect on the mobility of the users.

Evaluating the works that were presented in this article, one can infer that, in general, almost all the smart walkers have an assistive navigation system with sensors that detect obstacles, as well as, a design that has been studied to provide and improve a stable gait. This factor is possible with different designs of the guide platform that can have, for example, a forearm support. Another aspect that increases stability is the fact that electronics and other heavy components are put on the lower base of the walkers, giving a greater balance and stability to the device.

Thus, rollators can be easily augmented with simple and relatively low cost instrumentation technologies to provide a wide range of functionality and gait characteristics as Smart walkers, and avoid to inadequately resort to alternative devices, thus contributing to the maintenance or to the improvement of the physical and cognitive capabilities of the user.

\section{References}

[1] World Population Ageing 1950-2050. Population Division, DESA, United Nations.[http://www.un.org/esa/population/publications/worldageing19502050/pdf/81cha pteriii.pdf.] Acessed in 25 May 2010.

[2] Ceres R :Las tecnologías de apoyo para la vida independiente de los mayores. Entre MayoresEM 2007, 10-11.

[3] Raya R, Frizera A, Pastor J, Ceres R, Calderón L: Configuración de un sistema ultrasónico multisensor para navegación asistida de niños con deficiencias neuromotoras. Actas de las XXVIII Jornadas de Automática, 2007.

[4] Ceres R, Pons J L, Calderón L, Jiménez AR, Azevedo L: A robotic vehicle for disabled children. IEEE Engineering in Medicine and Biology Magazine 2005, 24(6):5563.

[5] Lacey G, Dawson-Howe K: Evaluation of Robot Mobility Aid for the Elderly Blind. Proceedings of the Fifth International Symposium on Intelligent Robotic Systems, 1997.

[6] Duxbury A: Gait Disorders and Fall Risk: Detection and Prevention. Comp Ther, 
2000, 26(4):238-245.

[7] Axer H, Axer M, Sauer H, Witte O, Hagemann G: Falls and gait disorders in geriatric neurology. Clinical Neurology and Neurosurgery 2010, 112, 265-274.

[8] Lundin-Olsson L, Nyberg L, Gustafson Y: Stops walking when talking as a predictor of falls in elderly people. Lancet 1997, 349: 617.

[9] Anke H, Snijders P, van de Warrenburg N, Bastiaan R, Bloem: Neurological gait disorders in elderly people: clinical approach and classification. Lancet Neurol 2007, 6(1):63-74.

[10] Constantinescu R, Leonard C, Deeley C, Kurlan R. : Assistive devices for gait in Parkinson’s disease. Parkinsonism and Related Disorders 2007, 13:133-138.

[11] Pires G, Rui A, Urbano N, Almeida A: Robchair: A Powered Wheelchair using a Behaviour-Based Navigation. Proc. IEEE Int. Workshop on Advanced Motion Control (AMC'98) 1998, 536-541.

[12] Reis L, Braga R, Sousa M, Moreira A : IntellWheels MMI: A Flexible Interface for an Intelligent Wheelchair. Lecture Notes in Computer Science 2010, 5949/2010:296307, DOI: 10.1007/978-3-642-11876-0_26.

[13] Nisbet PD, Craig J, Odor JP, Aitken, S: “Smart” wheelchairs for mobility training. Technology and Disability 2005, 49-62.

[14] Image wheelchair [http://www.wheelchairslift.net/wheelchair/manual-wheelchairs3/]. Acessed in 29 May 2010.

[15] Tanaka K, Matsunaga K, Wang HO: Electroencephalogram-based control of an electric wheelchair. IEEE Transactions on Robotics and Automation 2005, 21:762-766.

[16] Frizera A, Celeste WC, Martins VR, Bastos-Filho TF, Sarcinelli-Filho M: Humanmachine interface based on electro-biological signals for mobile vehicles. In Proceedings of the International Symposium on Industrial Electronics 2006.

[17] Ferreira A, Silva RL, Celeste WC, Bastos Filho TF, Sarcinelli Filho M: Humanmachine interface based on muscular and brain signals applied to a robotic wheelchair. Journal of Physics 2007. DOI: 10.1088/1742-6596/90/1/012094.

[18] Andrzej S , Cichocki, Riken-Toyota Collaboration Lab Head. Journal Article 2009. [http://cacm.acm.org/news/43117-thought-controlled-wheelchair/fulltext]. Acessed in 19 May 2010.

[19] Exmovere.[http://www.exmovere.com/mobility.html] Acessed in 19 May 2010.

[20] Medical Supplies \& Equipment Company. [http://rehabilitation-products.medicalsupplies-equipment company.com/PPF/page_ID/195/article.asp]. Acessed in 29 May 2011.

[21] Novandy B, Yoon J, Manurung A: Interaction Control of a programmable FootpadType Gait Rehabilitation Robot for Active Walking on Various Terrains. IEEE 11th 
International Conference on Rehabilitation Robotics Kyoto International Conference Center 2009, 23-26.

[22] Colombo G: Treadmill training of paraplegic patients using a robotic orthosis. Journal of Rehabilitation Research and Development 2000, 37 (6): 693-700.

[23] Luenenburger L, Colombo G, Riener R: Biofeedback for robotic gait rehabilitation. Journal of NeuroEngineering and Rehabilitation 2007, 4:1.

[24] Chin LF, Lim WS, Kong KH: Evaluation of robotic-assisted locomotor training outcomes at a rehabilitation centre in Singapore. Singapore Med J 2010 51(9): 709-715.

[25] Schwartz I, Sajin A, Fisher I, Neeb M, Shochina M, Katz-Leurer M, Meiner Z: The Effectiveness of Locomotor Therapy Using Robotic-Assisted Gait Training in Subacute Stroke Patients: A Randomized Controlled Trial. Medical Association Journal 2009, 1:516-523.

[26] Swinnen E, Duerinck S, Baeyens J, Meeusen R, Kerckhofs E: Effectiveness of robotassisted gait training in persons with spinal cord injury: a systematic review. Journal of Rehabilitation Medicine 2010, 42:1-7.

[27] Veneman J, et al.: Design and Evaluation of the LOPES Exoskeleton Robot for Interactive Gait Rehabilitation. IEEE Transactions on Neural Systems and Rehabilitation Engineering 2007, 15 (3):379-386.

[28] Leahy, Theresa E. Impact of a limited trial of walking training using body weight support and a treadmill on the gait characteristics of an individual with chronic, incomplete spinal cord injury. Physiotherapy theory and practice 2010, 26(7):483-489.

[29] Pillar, Thomas, Dickstein R, Smolinski, Z: Walking Reeducation with Partial Relief of Body Weight in Rehabilitation of Patients with Locomotor Disabilities. Journal of Rehabilitation Research and Development 1991, 28(4):47-52.

[30] Veg A, Popovic D: Walkaround: Mobile Balance Support for Therapy of Walking. IEEE Transactions on Neural Systems and Rehabilitation Engineering 2008, 16(3).

[31] Bouri M, Stauffer Y, Schmitt C, Allemand Y, Gnemmi S, Clavel R, Metrailler P, Brodard R: The WalkTrainer: A Robotic System for Walking Rehabilitation. IEEE International Conference on Robotics and Biomimetics. ROBIO '06.

[32] The Rehabilitation Institute of Chicago. (2005). [http://www.kineadesign.com/portfolio/kineassist/]. Acessed in 19 May 2011.

[33] Seo K, Lee J: The development of two mobile gait rehabilitation systems. IEEE Transactions on Neural Systems and Rehabilitation Engineering 2009,17(2):156-166.

[34] LiteGait [http://litegait.com/research.html]. Acessed in 30 May 2011.

[35] Schmidt H, Werner C, Bernhardt R, Hessen S, Kruger J: Gait rehabilitation machines based on progammable footplates. Journal of NeuroEngineering and Rehabilitation 2007. [36] Monaco, V., Jung, J. H., Macrì, L., Bagnato, S., Micera, S., Carrozza, J. H., Galardi, 
G.. Robotic system for gait rehabilitations of stroke patients during the acute phase. IEEE International Conference on Rehabilitation Robotics 2009.

[37] Nudo RJ, Milliken GW: Reorganization of movement representation in primary motor cortex following focal ischemia infarcts in adult squirrel monkeys. Journal of Neurophysiology 1996, 75:2144-2149.

[38] Dollar A, Herr H: Lower Extremity Exoskeletons and Active Orthoses: Challenges and State-of-the-Art. IEEE Transactions on Robotics 2008, 24(1).

[39] Pons, J. Wearable Robots: Biomechatronic Exoskeletons. John Wiley and Sons 2008.

[40] Kawamoto H, Lee S, Kanbe S, Sankai Y: Power assist method for HAL-3 using EMG-based feedback controller. In Proc. IEEE Int. Conf. Syst., Man, Cybern. 2003, 1648-1653.

[41] ARGO, Medical Tecnologies Ltd. [http://www.argomedtec.com/products.asp]. Acessed in 19 June 2010.

[42] Pratt JE, Krupp BT, Morse CJ, Collins SH: The RoboKnee: An exoskeleton for enhancing strength and endurance during walking. In Proc. IEEE Int. Conf. Robot. Autom. 2004, 2430-2435.

[43] Ferris D, Czerniecki J, Hannaford B: An ankle-foot orthosis powered by artificial pneumatic muscles. Journal of Applied Biomechanics 2005, 21 (2):189-197.

[44] Blaya JA, Herr H: Control of a variable-impedance ankle-foot orthosis to assist dropfoot gait. IEEE Trans Neural Syst Rehabil Eng 2004, 12(1):24-31.

[45] Moreno J, Rocon E, Ruiz AF, Brunetti F, Pons JL: Design and implementation of an inertial measurement unit for control of artificial limbs: application on leg orthoses. Sensors and Actuators B 2006, 118:333-337.

[46] Banala S, Agrawal S, Fattah A, Krishnamoorthy V, Hsu W, Scholz J, Rudolph K: Gravity-Balancing Leg Orthosis and Its Performance Evaluation. IEEE Transactions on robotics 2006, 22(6): 1128-1239.

[47] Hoo FW, Demonbreun D, Weiss BD: Ambulatory devices for chronic gait disorders in the elderly. American Family Physician 2003, 67(8):1717-1724.

[48] Spenko M, Yu H, Dubowsky S: Robotic personal aids for mobility and monitoring for the elderly. IEEE Transactions in Neural Systems and Rehabilitation Engineering 2006, 14(3):344-351.

[49] Borenstein J, Ulrich I: The guidecane - a computerized travel aid for the active guidance of blind pedestrians. In Proceedings of the IEEE International Conference on Robotics and Automation 1997,1283 - 1288.

[50] Crutche: [http://druffmix.com/soul-on-crutches/] Acessed in 30 May 2010.

[51] Costa N, Caldwell D: Control of a biomimetic soft-actuated 10dof lower body exoskeleton. In Proceedings of the First IEEE/RAS-EMBS International Conference on 
Biomedical Robotics and Biomechatronics, 2006, 495-501.

Molloy,

D..

Boomer.

[http://student.designawards.com.au/application_detail.jsp?status=6\&applicationID=5541

].Acessed in 30 May 2010.

[53] U-Step. [http://www.ustep.com/walker.htm]. Acessed in 30 May 2010.

[54] Cub E, Moore CG, Leurgans S, Goetz CG: Wheeled and standard walkers in Parkinson's disease patients with gait freezing. Parkinsonism Relat Disord 2003, 10:9-14.

[55] Standard Walker: [http://www.technomedic.ca/]. Acessed in 30 May 2010.

[56] Bateni H, Maki B: Assistive Devices for Balance and Mobility: Benefits, Demands, and Adverse Consequences. Arch Phys Med Rehabil 2005, 86.

[57] Marincek C, Buhler C, Knops H, Andrich R: (2001) Assistive Technology: Added Value to the Quality of Life. Assistive Technology Research Series 2001.

[58] Morris AC, Donamukkala RR, Kapuria A, Steinfeld A, Matthews J, Dunbar-Jacobs J, Thrun S: A robotic walker that provides guidance. In Proceedings of the 2003 IEEE Conference on Robotics and Automation 2003, 25-30.

[59] Frizera A, Abellanas A, Ceres R, Pons JL, Raya R: Study and Characterization of Feet Kinematics in Walker Assisted Gait. Revista Iberoamericana de Automatica e Informatica Industrial (RIAI) 2009, 6(4): 74-84.

[60] Tan R, Wang S, Jiang Y, Ishida K, Nagano M: Adaptive Controller for Motion Control of an Omni-directional Walker. Proceedings of the 2010 IEEE International Conference on Mechatronics and Automation. Xi'an, China, 156-161.

[61] Frizera A, Ceres R, Pons J.L, Abellanas A, Raya R: The smart walkers as geriatric assistive device. The SIMBIOSIS purpose. Gerontechnology (Valkenswaard) 2008, 7:108-115.

[62] Alwan M, Wasson G, Sheth P, Ledoux A, Huang C: Passive derivation of basic walker-assisted gait characteristics from measured forces and moments. In Proceedings of the 26th Annual International Conference of the IEEE EMBS 2004, 2691- 2694.

[63] Ceres R, Pons JL, Calderón L, Mesonero-Romanos D, Jiménez VF, Sánchez X, Abizanda P, Saro B, Bonivardo G: Andador activo para la rehabilitación y el mantenimiento de la movilidad natural. IMSERSO, Estudios I+D+I 2005, 25:1 - 8.

[64] Borgolte U: A novel mobility aid for independent daily living of elderly people. In Proceedings 5th European Conference for the Advancement of Assistive Technology (AAATE) 1999, $267-271$.

[65] Frizera A: Interfaz Multimodal para modelado, estudio y asistencia a la marcha mediante andadores robóticos -Phd Thesis, 2010, Universidad de Alcalá.

[66] Tagawa Y, Shiba N, Matsuo S, Yamashita T: Analysis of human abnormal walking using a multi-body model joint models for abnormal walking and walking aids to reduce 
compensatory action. Journal of Biomechanics 2000, 33:1405-14.

[67] Scherer MJ: The impact of assistive technology on the lives of people with disabilities. In: Gray DB, Quatrano LA, Lieberman ML, editors. Designing and using assistive technology in human perspective. Baltimore: PH Brooks, 1998, 99-116.

[68] Mann WC, Granger C, Hurren D: An analysis of problems with walkers encountered by elderly persons. Phys Occup Ther Geriatr 2005, 13:1-23.

[69] Charron PM, Kirby RL, MacLeod DA: Epidemiology of walker related injuries and deaths in the United States. Am J Phys Med Rehab 1995, 74:237-9.

[70] Lacey G, MacNamara S, Dawson-Howe KM: Personal adaptive mobility aid for the infirm and elderly blind. Lecture Notes in Computer Science 1998, 1458:211 - 220.

[71] MacNamara S, Lacey G: A smart walker for the frail visually impaired. In Proceedings of IEEE International Conference on Robotics and Automatonomous 2000.

[72] Cortés U, Martínez-Velasco A, Barrué C, Martín X, Campana F, Annicchiarico R, Caltagirone C: Towards an intelligent service to elders mobility using the i-Walker. Proc. of AAAI Fall Symposia AI in Eldercare: New Solutions to Old Problems 2008, Washington, USA.

[73] Wasson G, Gunderson J, Graves S: Effective shared control in cooperative mobility aids. In Proceedings of the Fourteenth International Florida Artificial Intelligence Research Society Conference 2001, 1:1-5.

[74] Dubowsky S, Genot F, Godding S, Kozono H, Skwersky A, Yu H, Yu LS: PAMM A Robotic Aid to the Elderly for Mobility Assistance and Monitoring. In: IEEE International Conference on Robotics and Automation 2000, San Francisco, 570 -576.

[75] Patel M, Miro JV, Dissanayake G: Activity Recognition from the Interactions between an Assistive Robotic Walker and Human Users. HRI 2011.

[76] McDonald MJ: Active Research Topics in Human Machine Interfaces. Technical Report 2000. Sandia National Labs., Albuquerque, NM (US).

[77] Bueno L, Brunetti F, Frizera A, Pons JL: Human-Robot Cognitive Interaction. In: Wearable Robots: Biomechatronic Exoskeletons. 1 ed. John Wiley \& Sons, 2008 1:87126.

[78] Hashimoto H, Sasaki A, Ohyama Y, Ishii C: Walker with hand haptic interface for spatial recognition. In Proceeding of the ninth IEEE International Workshop on Advanced Motion Control 2006, 311-316.

[79] Rentschler AJ, Simpson R, Cooper RA, Boninger ML: Clinical evaluation of Guido robotic walker. Journal of Rehabilitation Research Development 2008, 45(9):1281-1294. [80] Shi F, Cao Q, Leng C, Tan H: Based On Force Sensing- Controlled Human-Machine Interaction System For Walking Assistant Robot. Proceedings of the 8th World Congress on Intelligent Control and Automation 2010, Jinan, China, 6528-6533. 
[81] Zhou W, Xu L, Yang J: An Intent-Based Control Approach for an Intelligent Mobility Aid. 2nd International Asia Conference on Informatics in Control, Automation and Robotics 2010, 54-58.

[82] McLachlan S, Arblaster J, Liu DK, Miro JV, Chenoweth L: A Multi-Stage Shared Control Method for an Intelligent Mobility Assistant. Proceedings of the 2005 IEEE 9th International Conference on Rehabilitation Robotics, 426-429.

[83] Chuy O, Hirata Y, Kosuge K :Active Type Robotic Mobility Aid Control Based on Passive Behavior. Proceedings of the 2007 IEEE/RSJ International Conference on Intelligent Robots and Systems. San Diego, CA, USA, 165-170.

[84] Gharieb W: Intelligent Robotic Walker Design. International Conference on Automation, Robotics and Autonomous Systems 2006, Sharm El Sheikh, Egypt.

[85] Lee G, Ohnuma T, Chong NY: Design and control of JAIST active robotic walker. Intel Serv Robotics, 125-135.

[86] Hirasawa M, Okada H, Shimojo M: The development of the plantar pressure sensor shoes for gait analysis. Journal Robot Mechatron 2007, 20(3):324-330.

[87] Wasson G, Gunderson J, Graves S, Felder R: An assistive robotic agent for pedestrian mobility. In Inter. Conf. on Autonomous Agents 2001, 169-173.

[88] Jiang Y, Wang S: Adapting Directional Intention Identification in Running Control of a Walker to Individual Difference with Fuzzy Learning. Proceedings of the 2010 IEEE International Conference on Mechatronics and Automation. Xi'an, China.

[89] Alwan M, Ledoux A, Wasson G, Sheth P, Huang C: Basic walker-assisted gait characteristics derived from forces and moments exerted on the walker's handles: Results on normal subjects. Medical Engineering \& Physics 2007, 29:380-389.

[90] Frizera A, Gallego JA, Rocon E, Pons JL, Ceres R: Extraction of user’s navigation commands from upper body force interaction in walker assisted gait. Biomedical Engineering Online 2010, 9(1):37.

[91]Martins M: Online control of a mobility assistance Smart walker. Master Thesis. Minho University, 2011.

[92] Geunho L, Eui-Jung J, Takanori O, Nak Young C, and Byung-Ju Y: JAIST Robotic Walker Control Based on a Two-layered Kalman Filter. IEEE International Conference on Robotics and Automation. Shangai, China, 2011, p. 3682-3687. 